Editorial

\title{
Endometrial Polyps - When Should Hysteroscopic Resection Be Performed?
}

\section{Pólipos endometriais - quando a resseção histeroscópica deve ser realizada?}

\author{
Júlia Kefalas Troncon ${ }^{1}$ Ana Carolina Tagliati Zani ${ }^{1}$ \\ Júlio Cesar Rosa-e-Silva ${ }^{1}$ \\ ${ }^{1}$ Department of Obstetrics and Gynecology, Faculdade de Medicina \\ de Ribeirão Preto, Universidade de São Paulo - USP, Ribeirão Preto, \\ SP, Brazil \\ Rev Bras Ginecol Obstet 2016;38:315-316.
}

Francisco José Candido-dos-Reis ${ }^{1}$

The prevalence of endometrial polyps in postmenopausal women can be as high as $35 \%$, and it has been steadily increasing with the wide dissemination of ultrasound in the routine gynecological practice. ${ }^{1}$ Endometrial polyps are important because they can cause symptoms, and might be associated with endometrial cancer. The percentage of malignant lesions found in association with the polyps, or even within them, is 2.5 to $3 \%$, and can be higher in some populations. Risk factors for malignancy include advanced age, menopausal status, size of the lesion, hypertension, obesity and the presence of postmenopausal bleeding. ${ }^{2,3}$ Selective modulators of estrogenic receptors, such as tamoxifen, also play a role in the increased risk of endometrial cancer. ${ }^{4}$

Hysteroscopic biopsy is the gold standard for evaluation and diagnosis, since blind dilation and curettage have very low accuracy for detection of focal lesions, and the treatment is also performed hysteroscopically. ${ }^{5,6}$ However, even though hysteroscopy is a safe procedure, it is considered invasive, with risk of complications. In this way, when considering asymptomatic polyps with low risk of associated cancer, we must question whether resection is mandatory.

We performed a systematic review of the literature, searching for studies that could help in such clinical decisions. Four databases were searched (PUBMED, Scielo, SCOPUS and ISI). The goal was to review all randomized controlled clinical trials on hysteroscopic polypectomy in postmenopausal patients with and without symptoms that had diagnoses of malignancy included in the outcomes. Two independent researchers performed the search (J.K.T. and A. C.T.Z). As a research tool, distinct combinations of the different following keywords and terms were used: endometrial polyps; treatment; menopause; postmenopausal bleed-

Address for correspondence Julio Cesar Rosa e Silva, MD, PhD, Department of Obstetrics and Gynecology, USP, Av. Bandeirantes, 3900, Ribeirão Preto, SP, 14049-900, Brazil (e-mail: juliocrs@usp.br). ing; endometrial cancer; and hysteroscopy. Studies with patients in reproductive age and premenopausal, as well as studies concerning patients using tamoxifen, were not considered relevant for the purposes of the review, and were therefore excluded. The search was also restricted to studies in English published after the year 2000. A preliminary analysis of the title as well of the abstract of the each study was made, and if considered relevant, the full text was further analyzed. In such cases, the cited references of the article were also searched.

After a thorough review of the literature, no randomized trial was found; consequently, we do not get a definitive answer for that question. So, up to the present date, the individual management of postmenopausal women with endometrial polyps has to be based on the balance between benefits and risks. For this purpose, we suggest that the approach of these patients should consider the different situation, as follows.

For asymptomatic women, the prevalence of endometrial cancer is very low, ${ }^{7}$ and there is no current recommendation for endometrial cancer screening. Moreover, for the rare cases that may arise, the diagnosis before clinical symptoms has no significant impact on patient survival. ${ }^{8-10}$ Based on these evidences, hysteroscopic surgery is not recommended for asymptomatic endometrial polyps.

On the other hand, the literature shows that bleeding is the main risk factor associated with malignancy in endometrial polyps. However, even in these cases, the incidence of cancer is low. $3,11,12$ Furthermore, from a pathophysiological point of view, the presence of bleeding cannot be attributed with certainty to the polyp itself. The polyp arises from a combination of genetic and hormonal factors, and from an
Copyright (c) 2016 by Thieme Publicações License terms

Ltda, Rio de Janeiro, Brazil 10.1055/s-0036-1586488. ISSN $0100-7203$. 
unbalance in proliferation and apoptosis regulation mechanisms. ${ }^{13}$ Therefore, one can assume that the surrounding endometrium is potentially dysfunctional and could develop other pathologies, or even present with bleeding due to endometrial atrophy. For symptomatic women with low surgical risk, hysteroscopic polypectomy is a good option. However, in cases with comorbidities, clinical follow-up is also acceptable.

Considering the clinical relevance and prevalence of endometrial polyps, we believe that well controlled trials on polypectomy through hysteroscopic procedure in postmenopausal patients, particularly when asymptomatic, are imperative.

\section{References}

1 Salim S, Won H, Nesbitt-Hawes E, Campbell N, Abbott J. Diagnosis and management of endometrial polyps: a critical review of the literature. J Minim Invasive Gynecol 2011;18(5):569-581

2 Ben-Arie A, Goldchmit C, Laviv Y, et al. The malignant potential of endometrial polyps. Eur J Obstet Gynecol Reprod Biol 2004; 115(2):206-210

3 Costa-Paiva L, Godoy CE Jr, Antunes A Jr, Caseiro JD, Arthuso M, Pinto-Neto AM. Risk of malignancy in endometrial polyps in premenopausal and postmenopausal women according to clinicopathologic characteristics. Menopause 2011;18(12):1278-1282

4 Lee SC, Kaunitz AM, Sanchez-Ramos L, Rhatigan RM. The oncogenic potential of endometrial polyps: a systematic review and meta-analysis. Obstet Gynecol 2010;116(5):1197-1205
5 Svirsky R, Smorgick N, Rozowski U, et al. Can we rely on blind endometrial biopsy for detection of focal intrauterine pathology? Am J Obstet Gynecol 2008;199(2):115.e1-115.e3

6 Ribeiro CT, Rosa-E-Silva JC, Silva-de-Sá MF, et al. Hysteroscopy as a standard procedure for assessing endometrial lesions among postmenopausal women. Sao Paulo Med J 2007;125(6):338-342

7 Breijer MC, Peeters JAH, Opmeer BC, et al. Capacity of endometrial thickness measurement to diagnose endometrial carcinoma in asymptomatic postmenopausal women: a systematic review and meta-analysis. Ultrasound Obstet Gynecol 2012;40(6):621-629

8 Seebacher V, Schmid M, Polterauer S, et al. The presence of postmenopausal bleeding as prognostic parameter in patients with endometrial cancer: a retrospective multi-center study. BMC Cancer 2009;9:460

9 Jacobs I, Gentry-Maharaj A, Burnell M, et al. Sensitivity of transvaginal ultrasound screening for endometrial cancer in postmenopausal women: a case-control study within the UKCTOCS cohort. Lancet Oncol 2011;12(1):38-48

10 Rimel BJ, Burke WM, Higgins RV, Lee PS, Lutman CV, Parker L. Improving quality and decreasing cost in gynecologic oncology care. Society of gynecologic oncology recommendations for clinical practice. Gynecol Oncol 2015;137(2):280-284

11 Antunes A Jr, Costa-Paiva L, Arthuso M, Costa JV, Pinto-Neto AM. Endometrial polyps in pre- and postmenopausal women: factors associated with malignancy. Maturitas 2007;57(4):415-421

12 Baiocchi G, Manci N, Pazzaglia M, et al. Malignancy in endometrial polyps: a 12-year experience. Am J Obstet Gynecol 2009;201(5): 462.e1-462.e4

13 Maia H Jr, Maltez A, Studart E, Athayde C, Coutinho EM. Ki-67, $\mathrm{Bcl}-2$ and p53 expression in endometrial polyps and in the normal endometrium during the menstrual cycle. BJOG 2004;111(11): $1242-1247$ 